\title{
I, Humanity
}

Haubold $\mathrm{HJ}^{*}$ and Werner R. Balogh

Office for Outer Space Affairs, United Nations, Austria

*Corresponding author: Haubold HJ, Office for Outer Space Affairs, United Nations, Austria, Tel: +43-1-26060-5830; E-mail: hans@neutrino.aquaphoenix.com Rec date: November 03, 2015; Acc date: November 05, 2015; Pub date: November 09, 2015

Copyright: ( 2015 Haubold $\mathrm{HJ}$, et al. This is an open-access article distributed under the terms of the Creative Commons Attribution License, which permits unrestricted use, distribution, and reproduction in any medium, provided the original author and source are credited.

\section{Editorial}

On a continuing basis in the past twenty five years we have reported on the long-term initiative of the United Nations Programme on Space Applications of the Office for Outer Space Affairs of the United Nations, known under the term 'basic space science', covering the three pillars of research, education, and applications of fundamental knowledge for the benefit of human kind. The research part of this initiative was exercised through annual United Nations workshops, hosted and supported by member States and their respective space agencies (http://www.unoosa.org/oosa/en/ourwork/psa/bssi/ index.html). The education part was exercised through UN-affiliated Regional Centres for Space Science and Technology Education (http:// www.unoosa.org/oosa/en/ourwork/psa/regional-centres/index.html). The time range of this initiative extended from 1990 to 2015 with most recent activities hosted by Austria (http://www.unoosa.org/oosa/en/ ourwork/psa/schedule/2014/

austrian_symposium_space_science.html) and Japan (http://aas.org/ posts/news/2015/03/report-unjapan-workshop-space-weather).

To be released in November (2015) but already available for individual distribution is the book with the above title, written by a renowned researcher and educator in astronomy and astrophysics:

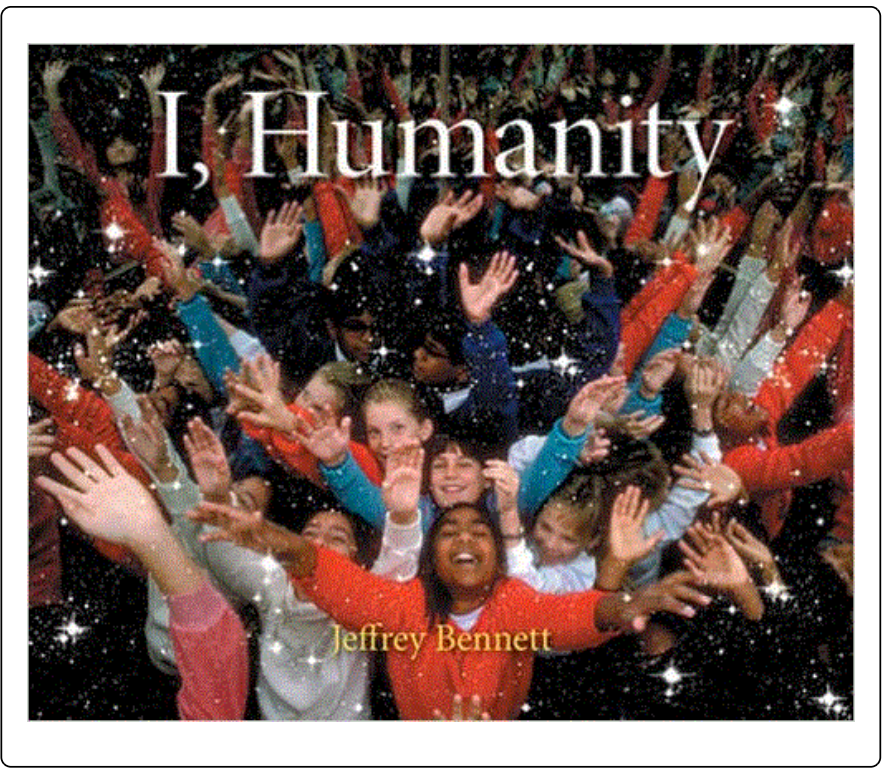

The beautifully illustrated, 32-page book tells the story of how humanity has gone from ancient conceptions of a small, flat Earth to our modern understanding that we live on one planet, orbiting one star, in a vast and amazing Universe. Using a first person narrative, the story is told in a way that will make every child of every culture feel that they are a part of this fantastic journey of discovery through history. In this sense, the book summarizes what the UN initiative has sought to achieve over a quarter century, building upon past dissemination efforts that have included thousands of ESA/NASA Hubble Space Telescope DVDs and comprehensive in-depth curricula for space science and technology education (http://www.unoosa.org/ oosa/en/ourwork/psa/regional-centres/study_curricula.html). Author/ astrophysicist Jeffrey Bennett will make available a limited number of free copies of this book through the Office for Outer Space Affairs of the United Nations. In addition, the book is scheduled to be launched in December to the International Space Station, where it will be read aloud by astronauts for the Story Time from Space program (http:// storytimefromspace.com), with the video reading posted freely on the web for educational use anywhere in the world. The book is also available in Spanish (both print and e-book) and Japanese (e-book only). Author Jeffrey Bennett also invites translations into other languages, as he can offer low-cost book production and donation of copies for educational use; contact him directly (jeff@bigkidscience.com) if you are interested in this possibility. 